\title{
Perceptions of Instructors and Students to Online Education at a Rural University
}

\author{
Sevim Kutlutürk \\ Inönü University, Malatya, Turkey
}

\begin{abstract}
The popularity of technology has allowed universities to make changes through their educational system in recent years. Some transitioned from face-to-face instruction to online instruction. The aim of this study is to investigate the perceptions of both the instructors and the students as regards second language acquisition through online education at a rural university. The study was implemented in the context of teaching and learning English as a second language in an online education environment. The course material is based on The Net Languages Learning Platform, which is available at http://ide.yok.gov.tr/, and the course level is general English pre-elementary. Both quantitative and qualitative methods were used in this study. For quantitative data collection, a questionnaire was employed to understand the reasons for low student attendance on online courses. For qualitative research method, observation was carried out, and interviews are designed as data collection techniques. Purposive selection was used for selection of the participants. The findings revealed that online education needs to be modified. The students are eager to improve their second language competencies; however, they do not want to waste their time on an easy course level.
\end{abstract}

Keywords: online education, online instruction in ESL, distance education in ELT, online education and face-to-face education

\section{Introduction}

The world is changing rapidly through technology. We are online more than we are off-line during the day. Technology provides opportunities for humans to become aware of what is going on around them, for example, just by touching the screen of a smart phone. How many times a day do individuals check their email, log into Facebook or use Twitter? It is countless times. National Geographic declared that 2.5 billion people in the world would use the Internet by 2013. Both social life and education are being transformed by utilising technology.

Widespread use of technology has led to some changes in the educational system such as web-enhanced, computer-based, and online instruction. Some instructors may consider it an easy way to earn money. Instructing from your kitchen dressed in casual clothes may seem a fantastic idea. However, the aim of this study is to understand the effectiveness of online instruction for second language acquisition among undergraduates at Inönü University, and to discuss the opinions of instructors and students on online education.

Online education, or distance education, gives the opportunity to both instructors and students to interact remotely. From this view, as Gurbuz (2014) stated, online education benefits those students who cannot travel 
to another city for education due to low economic status. Gurbuz (2014) reported that Anadolu University has been meeting the requirements of those students who are seeking to further their education since 1982 . He mostly explained the advantages of distance learning, but insufficiently dealt with the necessity of technical infrastructure.

At the time of this research, it was seen that a significantly negative aspect concerned the technical infrastructure at Inonu University, as online education was not readily accepted by students and instructors. The reason might be that the institution is new in terms of providing an online environment. Nevertheless, technical staff do not make an effort to provide technical support to the students and instructors. Lack of equipment means that the instructors waste time, and they may find the online instruction intimidating and stressful to manage (Crawford-Ferre \& Wiest, 2012).

\section{Background}

The pioneer in distance education in Turkey is Anadolu University. According to Höcük (as cited in Gurbuz, 2014), following the lead of Anadolu University, other universities in Turkey incorporated distance learning programmes such as Ankara University, Ahmet Yesevi University, Istanbul Technical University, Middle East Technical University, Istanbul Bilgi University, YüzüncüYıl University, Frat University, Sakarya University, Selçuk University, Gazi University, Ataturk University and, most recently, Inönü University. Overwhelmed by the work, instructors at Inonu University investigated the online education at the universities mentioned. However, they realised that some of these universities implemented their own content not purchased from abroad such as Inönü University. In particular, Sakarya University recently started distance learning, just before Inonu University formed its own online instruction material for ESL (English as a Second Language), and it has been successful in implementing a programme. English instructors at Inönü University proposed to the course leaders visiting Sakarya University to investigate more closely its online programme.

\section{Readiness for Online Instruction}

Hicks, Reid, and George (as cited in Tan, Nabb, Aagard, \& Kim, 2010) pointed out that recent technological improvements have led to changes in education strategies all over the world; in particular, higher education institutions have adopted these changes. On the other hand, the readiness of an institution and students' facilities should be considered before adopting changes. Inönü University is not ready for the adoption of an online environment for ESL, as students have poor access to technical devices and the Internet. Liu (as cited in Tan et al., 2010) stated that all the issues are web-based and computer-based; however, newer students are tech-savvy. Higher education institutions also need to keep up with online education progress to provide an adequate learning strategy for students who are interested in online education. Nevertheless, Inönü University students are not very tech-savvy and there is a lack of relevant equipment. On the other hand, some of the students want online education. From this point of view, Campell (2007) contends that online discussion provides a non-threatening environment for students who have anxiety speaking in front of a class. It is also stated by Banegas and Busleimán (2014) that online learning reduces anxiety, but lack of immediate feedback is a demotivating factor for students. 


\section{Research Questions}

In this study, three research questions are configured. The aim of the first two questions is to reveal both instructors' and students' perceptions on online education and its validity. The aim of the third question is to explore the reasons for low student attendance on online courses.

(1) What are the instructors' perceptions of online versus traditional instruction and their preference for an educational system?

(2) What are the students' attitudes to English language learning through online education?

(3) What might be the reason(s) for low student attendance in online courses?

\section{Methodology}

Both quantitative and qualitative methods were used in this study. For quantitative data collection, a questionnaire was conducted to understand the reasons for students' low attendance on online courses. For qualitative research method, observation was carried out, and interviews are designed as data collection techniques. The researcher, who has extensive teaching experience in the university, is familiar with the setting where the interviewees work and study. The interviews were recorded in Turkish, later transcribed and translated into English. Interviewees were allowed to take control from time to time. Purposive selection was used for the participants.

\section{Context of the Study}

The study was conducted in the context of teaching and learning English as a second language online at Inönü University. First-grade students of all proficiency levels have to enrol for online instruction with three credits. Each week the students have three consecutive course hours. The course material is based on The Net Languages Learning Platform, which is available at http://ide.yok.gov.tr/, and the course level is general English pre-elementary.

There is no obligation for the students to be online during the course as there is opportunity to watch video recordings of the lessons. The students can watch these videos whenever and wherever they want. They just need a computer and internet access. Instructors are allowed to teach the course in their office or a studio designed for online education. However, the number of studios is not the same as the number of instructors. In addition, the online instructors need to have a computer equipped with a camera. During the online course, the students are able to see and listen to the instructor by sitting opposite the computer. However, the instructors may be able to communicate with the students through the discussion board and by reading the students' messages. As the online instruction is every term, students need to take a mid-term and final test.

\section{Participants}

The researcher acted as a participant in the study. Participants' real names were not used in the study in line with research ethics. Therefore, participants were coded as T1, T2, and T3 for the instructors and S1, S2, S3, S4, and S5 for the students. As the institution transitioned from the traditional environment to online environment in the 2013-2014 academic year, the teachers were new to online education. It was just the second academic year. The students were from Mechanical Engineering faculty. 


\section{Instruments}

A newly designed questionnaire was given to the students, and it reflected the particular characteristics of the course. The researcher designed a semi-structured interview with open-ended and closed questions for both the instructors and the students. Participants T1, T2, and T3 were observed at the time of the online courses.

The researcher relied on experts' revisions to provide validity and reliability of the instruments used in the study. They all approved the research questions, the design of the questionnaire, and the questions asked in the interviews to reveal the participants' perceptions.

\section{Procedures}

\section{Data Collection}

As an online instructor, the researcher did not have opportunity to meet her students, as in a traditional classroom, during the course. This was the main reason why she conducted the questionnaire during students' mid-term exam (November 22, 2014). She had never before met her students face-to-face. She could only read their names and messages on the discussion board of the online course.

Participants were hosted one-by-one at different times, and interviewed in the researcher's office, a quiet and private place. Each interview took approximately 15 to 20 minutes. The interviews were audio-recorded in the native language, then transcribed and translated into English by the researcher. Semi-structured interviews were used, and the questions were altered during the interviews.

Participants T1, T2, and T3 were observed by the researcher during their online lessons. The study was employed in the first term of the 2014-2015 academic year.

\section{Data Analysis}

The questionnaire consisted of 10 interpretations designed to explain the reasons for low student attendance on online courses. Students were asked to mark one or more options that explain the reasons for not attending the lessons. The first enquired whether this was because attendance was not obligatory. The second and the third concerned the course level. The fourth was about their feelings towards English lessons. The fifth was about their technical facilities. The sixth was focused on their status as students. The seventh was about their preference for learning English. The eighth and the ninth concerned their views on the instructors and the efficacy of online courses respectively. The last focused on their opportunity to watch videos of their lessons whenever they wanted. The questionnaire was originally in Turkish. The researcher translated it into English for her research paper.

The data obtained from interviews and from observing the colleagues were analysed and coded by the researcher. A code words list was made and redundancies checked. As an online instructor and acting as a participant in the research, the collected data were not unexpected to the researcher.

\section{Findings}

The questionnaire was completed by 62 Mechanical Engineering students at the moment of conducting the research. Through the questionnaire, the researcher asked the participants to identify their reason(s) for nonattendance on the online courses by marking the appropriate sentences. The findings are presented in Table 1 as follows:

Table 1

Students' Responses to Explain the Reasons for Low Attendance on Online Courses

\begin{tabular}{lc}
\hline Reasons & Frequency \\
\hline (1) Attending the online lessons is not obligatory. & 27 \\
\hline
\end{tabular}


(2) Course level is too easy for me. 15

(3) Course level is too difficult for me. 5

(4) I don't like English lessons. 13

(5) Lack of technical facilities (Internet, computer, etc.).

(6) I am at work during the course time.

(7) I prefer face-to-face lessons.

(8) The course instructor is not proficient.

(9) I don't think online education contributes to my learning English.

(10) I have the chance to watch the videos of lessons whenever I want.

(11) Others:.

As can be seen in Table 1, all the participants fully completed the questionnaire. Half of them preferred face-to-face lessons, while $25 \%$ were finding the course level too easy and over $40 \%$ noted that it was not obligatory to attend online lessons. The researcher found that the majority of her students' preference was traditional classroom teaching.

The researcher can now elaborate the observational findings on her colleagues. T1 was in his private office, and the room was quiet and full of light. There were four armchairs, a bookcase, and an office desk. The computer screen, with a camera attachment, was on the office desk. T1 is a well-experienced instructor. He logged into the education system on time. At the beginning of the lesson, it could be seen through the discussion board that no one was online but he started the lesson. The lessons were recorded and later checked by a vice rector to determine whether they were performed. After a while, just a few students were online. It was observed that although they were online they did not sufficiently participate in the lesson. From time to time, T1 encouraged them to become involved in the lesson. There was no strong relationship between the instructor and the students. During the course time, some of the students logged out before the lesson was over. T1 seemed to be unsatisfied and had low student attendance.

T2 is a well-experienced instructor as well. His office is on the ground floor next to the researcher's office.T2's office has less light than T1's office, but it is quiet and well designed. He logged into the Net Language Learning platform on time, as did T1. The course period was 145 minutes. No students logged in during the course time. T2 seemed overwhelmed, even so he fulfilled his duty.

For the purpose of the study, the first research question was asked to T1, T2, and T3.

Research question 1: What are the instructors' perceptions of online versus traditional education and their preferences for educational system?

As all of the instructors are well-experienced and well-informed of students' profiles at the university, their responses were similar in some respects. As T1 was responsible for the syllabus of the online course, he was much more knowledgeable about the circumstances. He firstly pointed out the deficiency of technical support and internet access, and then continued:

Students are irrelevant to the circumstance. They assume the online class day as an off day. In traditional classes, half of the students could succeed to pass the exams, but they were capable to communicate abroad. Easiness of the online instruction syllabus allows the students to be more successful in the exams than the students in traditional classes. However, they are not capable to communicate abroad. For the reason they can watch the recorded videos of the lessons there is no interaction during the online courses, and they do not learn real English. Gazi University realised the inappropriateness of the online instruction and turned back to face-to-face instruction. (personal communication, January 5 , 2015) 
T2 completely rejected online education. He claimed that language could be accurately taught in a traditional classroom. T2 said in the interview:

We were trained as traditional teachers. In traditional classrooms, we use our gestures, voice and body language. We are the actors in the classroom. With eye contact, we can share our students' feelings. Positive relationship improves student behaviour and motivation to learn as well as their academic achievement. (personal communication, December 8 , 2014)

T2 also complained about low student attendance on online courses, and added that this should be obligatory. T2 mentioned that the university did not provide them with technical support. In addition, he decided to retire the following term.

T3 said in his interview:

Online education is a good system if the student presence is provided. The Net Languages Learning Platform is well designed, but it needs technical equipment for both instructors and students as well. There should be enough computers in the campus for students' use, and these computers need to have camera and speaker, so that they may be able to attend the courses visually and audibly. If technical support is provided by the institution, of course, I prefer online courses. 'Cause, while we teach, and they learn, we all learn to use technology by means of the computer. (personal communication, December 10, 2014)

T3 seemed to be pleased with the online education; however, he pointed out the lack of equipment. Furthermore, he reflected on the advantages of traditional education and said in the interview:

The textbook we used in the classes was web based, but we did not have classes designed with technical equipment for English lessons. If we had that kind of classes, traditional education would be better. Face-to-face education provides to the instructors to share their students' feelings. (personal communication, December 10, 2014)

Research question 2: What are the students' attitudes to English language learning through online education?

The second research question is related to online ESL students at Inönü University.

The participants were familiar with the researcher because they had attended the course several times. They honestly answered the research question. S1 said in the interview:

Course level is very easy, so I don't think it improves my English. I prefer face-to-face education. I have a higher level; if we were in a traditional class, you would help me to improve my English. (personal communication, November 22, 2014)

S1's perceptions need to be elaborated. All students are from different second language backgrounds. In traditional classrooms the instructor may be able to consider his or her students' English level and improve this by giving various activities and tasks. S2, another student from the Engineering Faculty, said the following in the interview:

I prefer blended learning. I tried to be online once, and after a while I logged out. We cannot learn English in this way. I know the necessity of English, but online instruction doesn't contribute anything to my English competence. I am going to enrol in an English course as soon as I graduate from the faculty. (personal communication, December 23, 2014)

S3, S4, and S5 explained their views in a similar way. The findings obtained from the students who participated in the research for the third question are presented in the following table. To code the interview, categories were developed. 
Research question 3: What might be the reason(s) for low student attendance on online courses?

Students' responses to the third question were coded as in Table 2 .

Table 2

Coded Information of Interviews With the Students

\begin{tabular}{ll}
\hline Participants & Categories \\
\hline S1 & Easy level \\
S2 & Easy level \\
S3 & Lack of equipment \\
S4 & Not obligatory \\
S5 & Not obligatory \\
\hline
\end{tabular}

As can be seen in Table 2, S3 pointed out in the interview that she did not have a computer and internet access to be online for the course. S4 and S5 explained that they assumed the day they had online English courses was a free day because attendance was not obligatory. S4 and S5 also added that they would attend if it was obligatory.

\section{Discussion}

The participants' responses and observational findings show that something is wrong with ESL education at the university. The researcher considers that ESL education is just performed as a fulfilment. There needs to be more contact with students. Student participants are from the Engineering Faculty, and they consider it necessary to learn English. From this point of view, the decision is to continue their English education after completing their bachelor's degrees. The university can meet their requirements. A better technical infrastructure needs to be put in place. The university should also consult with the instructors.

\section{Conclusion}

Online education in its current form is not applicable for instructors and students at Inönü University. The study has shown that both instructors and students need technical support. The university needs to provide an adequate environment to achieve successful education. With regard to the participants' responses, the most important finding in the study is that the course level and absence of obligation allow the students to have a lack of interest to the circumstance. Moreover, face-to-face lessons enable the instructors to recognise their students' feelings. Positive relationship improves students' behaviours and motivates them to learn as well as to seek academic achievement.

\section{References}

Banega, D. L., \& Busleiman G. M. (2014). Motivating factors in online language teacher education in Southern Argentina. Journal of Computers \& Education, 76, 131-142.

Campbell, N. (2007). Bringing ESL students out of their shells: Enhancing participation through online discussion. Business communication quarterly, 70(1), 37-43.

Crawford-Ferre, H. G., \& Wiest, L. R. (2012). Effective online instruction in higher education. The Quarterly Review of Distance Education, 13(1), 11-14.

Gurbuz, F. (2014). Students' views on distance learning in Turkey: An example of Anadolu University Open Education Faculty. Turkish Online Journal of Distance Education, 15(2), 18.

Tan, F., Nabb, L., Aagard, S., \& Kim, K. (2010). International ESL graduate student perceptions of online learning in the context of second language acquisition and cultural responsive facilitation. Adult Learning, 21(1-2), 9-14. 